\title{
ECOFEMINISMO. UNA REIVINDICACIÓN DE LA MUJER Y LA NATURALEZA
}

\author{
Ecofeminism. A demand of women and nature
}

María TARDÓN VigIL Universidad de Salamanca E-mail: mtardon@usal.es

Fecha de recepción: 6-III-2011

Fecha de aceptación: 17-III-2011

Resumen: A lo largo de la historia, la mujer ha sido, entre otras muchas cosas, creadora de conocimientos, productora de materia y guardiana de la biodiversidad. Los rasgos androcéntricos han ido transformando la cultura hasta desembocar en una crisis ecológica, razón de más por la cual se aborda la cuestión medioambiental desde el lado femenino (resaltando los valores de la naturaleza, la mujer, el animal, el sentimiento, la materia y el cuerpo). Fue Françoise d'Eaubonne la primera que usó el término "ecofeminismo" reclamando el cuerpo femenino como propiedad de una misma. Y a partir de esta premisa, diversos grupos de mujeres comenzaron a tomar conciencia sobre los riesgos de su salud, derivados del uso de pesticidas, fertilizantes y excesiva medicalización que repercuten sobre el cuerpo femenino. Y ya Karen Warren hace ecofeminismo desde la filosofía, concibe la diferenciación como inferioridad. La dominación es la peor de las formas de maltrato, y el medioambiente sufre cada día las consecuencias, cierta reflexión habría de impulsar una compasión especial por ese otro que nunca protesta.

Palabras clave: Rasgos androcéntricos, Françoise d'Eaubonne, ecofeminismo, Karen Warren, otro.

ABSTRACT: Throughout history, women have been knowledge creators, matter producers and biodiversity guardians, among other many things. Androcentric characteristics have transformed culture leading it into an ecological crisis. This is the main reason for approaching the environmental issue from the feminine side (highlighting nature values, women, animals, feelings, matter and body). Françoise d'Eaubonne was the first one who used the term "ecofeminism" claiming feminine body as their own property. And from this premise, various groups of women began to become aware of the risks to their health, arising from the use of pesticides, fertilizers and excessive medication that impact on the feminine body. Karen Warren sees ecofeminism from the philosophical point of view by 
conceiving differentiation as inferiority. Domination is the worst form of abuse, and the environment suffers the consequences every day. Certain thought should be encouraged: a special compassion for this other one that never complains.

Key words: Androcentric characteristics, Françoise d'Eaubonne, ecofeminism, Karen Warren, other.

\section{RECONOCIMIENTO DE LA MUjER EN CUATRO ANÁLISIS CONCEPTUALES}

En este artículo pretendo mostrar la figura de la mujer como productora de materia y guardiana de la biodiversidad entre otras muchas cosas. Y a la vez, analizar diferentes perspectivas conceptuales de por qué estas características no han sido suficientemente valoradas, convirtiéndola en un ser vulnerable privado en la mayoría de las veces de autonomía y quedando subordinada al gobierno del androcentrismo. Algunos puntos de vista no utópicos planteados por el ecofeminismo podrían dar solución a las desigualdades generadas por la actitud paternalista, que desembocan finalmente en una falta de reconocimiento, respecto a la mujer así como respecto al medioambiente.

"Filosofía ecofeminista" es el nombre que recibe la diversidad de estudios filosóficos que examinan las diferentes conexiones entre el feminismo y el medio ambiente." 1 La relación entre feminismo y medio ambiente, aunque a muchos pueda parecerles una conexión meramente excusadora como lucha contra el dominio y la subordinación, presenta no obstante ocho enfoques que han sido tratados a lo largo de los años y perfectamente documentados, desde el histórico hasta el político pasando por otros puntos de vista como pueden ser el ético o conceptual, por nombrar sólo algunos de ellos. La perspectiva que he elegido tratar es la conceptual, en la línea argumental de Karen Warren y la ética de Vandana Shiva, principalmente. Análisis a partir de los cuales pretendo dar respuesta a las dos principales preguntas que giran en torno a crítica hacia la "incompletud" del ecofeminismo: ¿cuál es el destino de la naturaleza? Y ¿debe ser protegida para ella o para los seres humanos liberados? ${ }^{2}$ Estas preguntas quedan poco claras para algunos, por eso, a lo largo del artículo, el método que he seguido es la hermenéutica de Paul Ricoeur, puesto que con ella se resuelven y despejan muchas de las dudas que pueden surgir en el camino.

La percepción sobre el género se haya siempre determinada por el momento histórico y social. Por eso la filosofía hay que mirarla con una hermenéutica de la sospecha. Y esta hermenéutica ha de caminar de la mano con el concepto de reconocimiento. La hermenéutica constituye una perspectiva, una forma de orientar la realidad. Ricoeur hizo mucho hincapié

1 Karen J. WARREN. Filosofías ecofeministas. Barcelona. Icaria. 2003. p. 12.

2 Witold JACORZYNSKY. Entre los sueños de la razón: filosofía y antropología de las relaciones entre hombre y ambiente. México. CIESAS. 2004. 
en el carácter narrativo de la experiencia vital de los individuos: producimos, creamos imágenes... para transmitir y dar un sentido, entre otras cosas, a la moral. El problema se presenta en que podemos encontrar ambigüedad en todo lo que posea sentido, por lo que la hermenéutica desempeña una función imprescindible en esta problemática: la función de la interpretación. La vida es compleja, ambigua... no viene acompañada de un manual que la explique de manera absoluta, y lo mismo ocurre cuando nos enfrentamos a los temas de género, no cabe aferrarse a un paradigma reduccionista. Lo mental se ha venido considerando siempre como superior, y respecto a su posicionamiento de dominio ante lo inferior, la historia "justifica" la subordinación de las mujeres, representativas del ente cuerpo. Subordinación que se ha ido perpetrando a través del lenguaje. No obstante, las ciencias humanas no vienen impregnadas de objetividad. La diferencia entre sexos, directamente no se trataba, ya que suponía un hecho.

Por eso, a través de la obra de Karen J. Warren, analizaré desde cuatro perspectivas conceptuales el modo en que mujer y naturaleza han sido clasificadas en la tradición intelectual, gobernada muchas veces por los dualismos organizados jerárquicamente.

\subsection{Primer anÁlisis conceptual. Dualismos}

El dualismo más conocido y generalizado es el de mente/cuerpo, es decir, los que hacen la civilización y las que proporcionan la reproducción. La percepción de que cada grupo ha de dedicarse a lo suyo. Es decir, mientras que los hombres hacen mejorar la civilización, la función de las mujeres se basa en mejorar la especie. ${ }^{3} \mathrm{O}$ el de civilizado/primitivo, en cuanto a que los segundos son inferiores a los primeros. ${ }^{4}$ Quizás el dualismo que más diferencias y desventajas ha generado en el mundo femenino sea el de producción/reproducción. El trabajo reproductivo y de cuidado se desarrolla casi exclusivamente en el ámbito doméstico, en el que hasta hace poco, y aun no en todos los casos, se carecía de remuneración económica, uno de los principales pilares para la independencia y la autonomía. Eso por no hablar del prestigio, que se sitúa exclusivamente en el ámbito público, cuyas decisiones, por cierto, rigen el ámbito privado. El mundo remunerado ha estado dominado por el hombre; las tareas desempeñadas

3 Cuando no estaba permitido el acceso de las mujeres a la universidad, la justificación era estudiada por una serie de pensadores denominados médicos-filósofos. Durante la Ilustración, fue muy conocido Cabanis.

4 Lévi-Strauss puso en duda este par en cuanto a la superioridad de uno sobre el otro. De hecho, en Pensamiento "primitivo" y mente "civilizada" afirma que "en la realidad las diferencias son extremadamente fecundas. El progreso sólo fue posible a partir de ellas". Y no considera primitivo el nivel de pensamiento de los pueblos que él prefiere denominar "ágrafos", puesto que estos dominaban materias impensables ahora para nuestras culturas (como ver el planeta Venus a la luz del día), que creen pertenecer a una élite superior por conducir coches y arreglar televisores. 
por las mujeres, al no formar parte del mercado contribuyendo al PIB, se consideran meramente reproductivas.

\subsection{Segundo anÁlisis. Fundamentación ontológica del poder}

Por otra parte, en el segundo análisis conceptual, se nos presenta "un conjunto (...) de creencias, valores, actitudes y suposiciones básicas que reflejan cómo uno se ve a sí mismo y a los demás" 5 . Los conceptos de poder parecen ser siempre vistos desde la dominación, la cual viene respaldada por una serie de justificaciones que favorecen la superioridad masculina sobre la mujer. En el Libro I de La Política de Aristóteles ya se hablaba de la fundamentación ontológica del dominio, el ser de las cosas según su naturaleza. Hay una clara idea de que quien hace las cosas con el cuerpo es inferior. Las mujeres hacen cosas con el cuerpo: dar a luz, alimentar... La tarea del ecofeminismo consiste en este caso en romper esas nociones preconcebidas que nos vienen dadas desde el nacimiento; pero basta abrir los ojos para comprender que no existe una lógica del poder regidora en el mundo humano. Ni para los humanos, ya que del mismo modo no existe un derecho o poder innato hacia la naturaleza, vulnerable de facto en el mismo grado que la mujer si se tiene en cuenta que ésta ha servido, tras la aparición de la propiedad privada, como medio de explotación más que como totalidad sin la cual no sería posible la vida.

A partir del estadio inferior de la barbarie, como lo denominó Engels, la caza dejó de ser un mero medio para el abastecimiento de víveres para convertirse en un lujo al alcance de unos pocos. Lo mismo ocurrió con el ganado, la agricultura... no hasta el punto de la ostentación pero sí en el sentido de la producción y los intereses económicos. Poco a poco se fue reproduciendo la idea de Max Weber del mundo como proceso de desencantamiento ${ }^{6}$. Todos los entes comienzan a convertirse en materia prima, o lo que es lo mismo, pueden ser reducidos a materia mensurable; en este caso hasta las personas, ya que muchas quedan reducidas a la condición de esclavos. Y de esta manera las mujeres qedaron relegadas también a la figura de esclavas en cuanto meras reproductoras y dadoras de placer.

\subsection{Tercer anÁlisis. Ética del medioAmbiente y ORGANización de} LA ECONOMÍA

Un tercer estudio conceptual ${ }^{7}$ propone la combinación de feminismo y ética medioambiental como creador de lenguajes y prácticas que tengan en cuenta el género sin promover la explotación en aquellos ámbitos identificados por lo general con lo masculino. Se viene estableciendo este vínculo entre ética medioambiental y feminismo porque el colectivo

5 Karen WARREN. Filosofías ecofeministas. Barcelona. Icaria. 2003. p. 15

6 Max WEBER. La ética protestante y el espiritu del capitalismo. Barcelona. Península. 1993

7 Karen WARREN. Filosofías ecofeministas. Barcelona. Icaria. 2003. p. 16 
femenino ha sido tradicionalmente el responsable del cuidado, y no es casualidad que la mayor parte de personas comprometidas con la atención hacia los animales y la conservación del medio sean mujeres. "En la India, la mujer está íntimamente integrada en la naturaleza, tanto en la imaginación como en la práctica $(. .$.$) la naturaleza (.$.$) es alimentada por lo femenino$ para producir vida y proporcionar los medios de subsistencia." ${ }^{\text {" Lo mismo }}$ ocurre entre las mujeres africanas cuando éstas llevan a cabo, en pequeña proporción, la distribución de la economía.

Está comprobado que las actividades llevadas a cabo por el colectivo femenino están destinadas a generar más ingresos. Todos los productos que obtienen de sus cultivos en las zonas rurales los utilizan para alimentar a sus familias, comprar medicinas a sus hijos, pagarles una educación, etc., mientras que en las ciudades este dinero se invierte principalmente en talleres y comercios. En el África Sub sahariana, las mujeres se organizaban económicamente mediante "el Tontín", cuyo único aval era la conciencia y confianza de las mujeres; esto les daba libertad e incluso iniciativa empresarial; en un caso concreto se llegó incluso a crear una empresa textil que proporcionó recursos suficientes para que los hijos pudieran estudiar. Más adelante comenzaron a imponerse los llamados "micro-créditos", que trajeron consigo la burocracia, frenando la actividad comercial de las mujeres. No quiero decir con esto que sean perjudiciales para el resto de la población, puesto que los "micro-créditos" están favoreciendo en una grado significativo el desarrollo de África, o mejor dicho, de los africanos. Pero la tasa de interés demandada por las entidades financieras es bastante alta, y las mujeres, antes que arriesgar con iniciativa empresarial, optan por brindar un futuro seguro a sus hijos. De nuevo se hace patente el vínculo entre mujeres y naturaleza con la economía de subsistencia que ellas llevan a cabo frente a la economía de mercado. Es Vandana Shiva la que rompe el estereotipo del feminismo occidental creando una filosofía que va desde el Sur hacia el Norte lanzando sus protestas contra el hombre colonizador, figura que termina por identificarse con el hombre occidental, aunque la crítica al mismo no era el objetivo inicial de Shiva. Su idea principal es la de respetar los ciclos de la naturaleza, permitir que la naturaleza o la tierra se recupere, sin forzarla. Cuando la tierra se concibe exclusivamente como materia prima, el principio femenino muere.

\footnotetext{
8 Vandana SHIVA. Abrazar la vida. Mujer, ecología y aupervivencia. Madrid. Horas y horas, D.L. 1995.

9 "Cada una entregaba lo que podía o lo que el grupo definía que se debía pagar de ante mano y ese dinero se reutilizaba para solucionar los problemas del grupo. La persona que se beneficiaba se comprometía a pagar la deuda en un plazo determinado". Natalia STOLZE. "Sadou Shakrah". Wanafrica. Febrero de 2007.
} 


\subsection{Cuarto análisis. Feminización de la naturaleza}

Finalmente, como cuarto estudio conceptual, K. Warren establece una comparación ente lo orgánico y lo científico en cuanto a la manera en que era concebida la naturaleza. ${ }^{10} \mathrm{La}$ feminización de la naturaleza y la naturalización de la mujer son dos metáforas que tras la revolución científica han perjudicado tanto a una como a otra, puesto que la naturaleza se ha convertido en ese ser vulnerable del que se puede abusar; la mujer, por su parte, ha sufrido las consecuencias de esa mecanización de lo orgánico, y al convertirse el hombre en el dueño de la técnica, el mundo femenino ha quedado subordinado a cuidar de lo orgánico, menos considerado económica y socialmente. La feminización de la naturaleza se está utilizando para explotarla, y no para ensalzar sus valores. La transgresión de la metáfora es por tanto el vínculo de colaboración entre feministas y éticos medioambientales.

\section{Actitud paternalista. De la Grecia Antigua a la Ilustración}

Respecto a la historia, es posible que muchos piensen en el tópico de no poder pensar otra cosa debido a la época, aunque ciertamente la historia de la filosofía no es inocente con respecto al género y a otras muchas desigualdades. Una de las formas de protegerse de los sistemas de poder es evitar la reflexión crítica sobre ellos. Por lo general, la mayoría de los temas conllevan polémica, y seguramente también Aristóteles polemizara con alguien. No obstante, la actitud que Aristóteles presenta en sus textos para con los esclavos y las mujeres no es de odio. Prueba de ello es su perspectiva de no usar la violencia, ni con unos ni con "otras", aunque no deje de concebir una desigualdad ${ }^{11}$. Se trata más bien de una autoridad serena, es decir, una actitud paternalista. A las mujeres, como a los esclavos, hay que enseñarles lo que tienen que hacer; el problema era la falta de reconocimiento ante la que eran sometidas, una carencia total de realización como personas.

Del mismo modo, y ya con la aparición de las democracias modernas, Jean Jacques Rousseau, partidario de los ideales ilustrados de igualdad y libertad, describía al ciudadano ideal con intensa participación política, y de manera directa, no representativa. "Para ello se necesitaba una mujer en el hogar que se ocupara de todas aquellas tareas que él no podría asumir."12 El filósofo no presentaba en este caso una postura de odio hacia la mujer,

10 Karen J. WARREN. Filosofías ecofeministas. Barcelona. Icaria. 2003. pp. 16-17

11 "Beauvoir parangona esta desigualdad entre las conciencias descrita por Hegel con la relación que existe entre varones y mujeres en la sociedad patriarcal. El hombre se autodesigna como el mismo, se autorreconoce como la conciencia libre del amo y designa a la mujer como otra, al igual que el esclavo, dependiente de la conciencia del amo como de su ideal" Celia AMORÓS. Feminismo y filosofía. Madrid. Síntesis. 2000. p. 144

12 Alicia H. PULEO. “Objetividad y género". Filosofía, género y pensamiento crítico. Valladolid. Universidad de Valladolid. 2000 
ya que admitía necesitar su ayuda en la casa para así los hombres poder desempeñar las demás funciones. Pero se está negando una vez más a la mujer su participación en el ámbito público, y con ello, el reconocimiento de sus capacidades. No siempre se llega a la humillación por los medios del odio y la agresión (que también), sino que existen otros muchos como este discurso del halago, en el que se resalta lo que hacen bien con el único fin de que no entren en otros asuntos. A las mujeres, "al negarles una educación más sensata, al alimentarlas sólo con cumplidos y bagatelas, al no permitirles ocuparse más que de juguetes, modas, adornos (...) ¿no les mostramos un desprecio muy real disfrazado bajo las apariencias de la diferencia y el respeto?"13 Más importante aún que estar enamorado y sentir deseo por la otra persona es el hecho de reconocerla y sentirse reconocido. ${ }^{14}$ Además del amor y los derechos, la mujer no puede ser totalmente plena si no disfruta de una estima social que le permita relacionarse con sus cualidades y capacidades positivamente. "El amor es una flor tierna que al menor soplo puede marchitar, la estima es un árbol profundamente enraizado que resiste las tempestades"'.

\section{REIVINDICACIÓN DE RECONOCIMIENTO}

Ciertamente, el lenguaje del Poder es determinante a la hora de medir la eficacia de una tradición; y el feminismo, pese a su afán de lucha durante la Revolución Francesa y más tarde en sus complicaciones con el marxismo, ha sido un concepto valorado con demasiada vacuidad. De ahí la renuencia del feminismo a considerarse siquiera una tradición. La crítica no generaliza un odio hacia el hombre, sino una lucha por la igualdad y la autonomía en aras de lograr el enterramiento definitivo de la invisibilidad de toda persona, especialmente de las mujeres, que en algunos terrenos como la ciencia, el espacio público, la literatura, etc. no han obtenido el reconocimiento merecido a lo largo de la historia. En Philosophie de la volonté II. Finitude et culpabilite $^{16}$, Ricoeur se refería a la apertura del alma en cuanto a la posibilidad que no se cierra ante ninguna cultura. La pretensión es trazar la línea entre lo admisible y lo no admisible, lo bueno y lo malo, lo digno y lo indigno... seguir una ética que proporcione un modelo argumentativo de acuerdo a los principios de autonomía, justicia y tolerancia. El ecofeminismo parece una corriente adecuada para resaltar esa vacuidad del concepto de "feminismo",

13 Alicia H. PULEO. Condorcet, De Gonges, De Lambert y otros. La Ilustración olvidada. La polémica de los sexos en el siglo XVIII. Barcelona. Anthropos. 1993. p. 79

14 Ver esquema de Honneth en la p. 129 de Struggle for Recognition. HONNETH, A Trad. Ingl. Joel Anderson. Struggle for Recognition. Oxford. Polity Press. 1995. Propone el amor, el respeto y la estima como pilares del reconocimiento.

15 Alicia H. PULEO. Condorcet, De Gonges, De Lambert y otros. La Ilustración olvidada. La polémica de los sexos en el siglo XVIII. Barcelona. Anthropos. 1993. pp. 80-81

16 Paul RICOEUR. Philosophie de la volonté II. Finitude et culpabilité. París. Éditions Montaigne. 1988. 
pero también del "ecologismo", igualmente ausente a lo largo del tiempo, pero muy relacionados ambos a la hora de reivindicar un reconocimiento que aún no se ha logrado del modo merecido. Feminismo y medioambiente se encuentran vinculados y recíprocamente comprometidos. Vandana Shiva se ha centrado en este vínculo desde el punto de vista ético, relacionando la desaparición de culturas con la pérdida de la diversidad en el contexto rural. A través de la ética, feminismo y ecologismo respetan lo sublime de la naturaleza desarrollando teorías que sirvan para actuar en el presente y reclamando una filosofía en femenino cuyos pilares fundamentales sean el cuidado y el reconocimiento del otro. Ya Ricoeur destacó la importancia del prefijo "re" del reconocimiento, que remarca esa repetición de conocer en la que se hace clara la presencia de algo o alguien. Es algo más que conocer, es romper el vacío que llenaba una concepción carente de algo que ahora hace notar su presencia. Vandana Shiva focaliza la atención en un cambio de concepción que no tiene por qué ser utópico, y que se basa en un lema principal: un cambio de la economía del dinero por la de la naturaleza. Cuando en 1977 se la criticó por frenar la economía abrazándose a los árboles junto con otras mujeres, su respuesta hizo referencia a este cambio de concepción que decía anteriormente; si el producto primero fueran las materias primas (agua, tierra, etc.) y no el dinero, la perspectiva de la producción sería totalmente diferente y favorecería la vida de muchos agentes que se ven arruinados por no alcanzar los mínimos exigidos por el sistema. Se evitaría de este modo el excesivo uso de productos químicos, cuyas principales repercusiones recaen sobre la vulnerabilidad femenina, puesto que el cuerpo de la mujer posee más materia grasa, donde se instalan los tóxicos provenientes de ciertos productos. Lo mismo ocurre con los cosméticos, ambientadores o perfumes, que actúan como disruptores endocrinos afectando a los niños antes de nacer, en el seno materno. La tecnologización y mercantilización está haciendo estragos, principalmente sobre la población femenina; de ahí que las personas más preocupadas por la concienciación acerca de los tóxicos que comienzan a formar parte del medio en forma de cosméticos y toxinas bioacumulativas también sean, en su mayoría, mujeres. Y al fin y al cabo, en Occidente basta con decantarse por el consumo ecológico libre de pesticidas compuestos por estas toxinas (aunque no resulte tampoco tarea fácil dado el alto coste); pero fuera de las fronteras europeo-occidentales la situación se agrava. En China, por ejemplo, las repercusiones negativas se multiplican por diez. Las obreras de economías emergentes respiran sin parar emanaciones tóxicas durante todo el tiempo que dura su jornada de trabajo. No se puede dar por tanto una solución clara a los problemas de género sin experimentar antes un cambio en la perspectiva comercial, es decir, fomentar el producto local en vez de encarecerlo, eso es proteger, para Shiva, la vida. ${ }^{17}$

17 “No puedes hacer volar tomates y lechugas alrededor del mundo y que la salud del planeta no lo acuse! La globalización es la principal causa del cambio climático. Cuantos más productos autóctonos consumamos, mejor para todos. España tiene un clima magnífico. 


\section{Conclusiones}

Cuidar la vida significa cuidar de los otros; el destino de la naturaleza depende de la acción humana. Desde el movimiento ecofeminista se valoran las actividades de cuidado, ligadas desde hace mucho tiempo a la mujer. A la ama de casa que cuida el hogar, a las hijas y hermanas que se ocupaban de mantener en orden lo necesario para que padres y hermanos desempeñaran sus tareas sin el estorbo de tener que dedicar las horas a actividades no remuneradas, etc. Pero se puede ir más allá de la sociedad más cercana, y hablar del mundo; un mundo enfermo en el que son patentes las diferencias entre Norte y Sur, entre civilizado y primitivo, entre naturaleza y cuerpo. Y con ello, el deterioro ambiental, que viene acentuándose y lo seguirá haciendo mientras la calidad de vida se mida por el consumo y no por los valores. El destino de la naturaleza, siguiendo la línea ecofeminista, sería el de un ser reconocido y con esto doy por zanjada la cuestión que planteaba al principio. Reconocer al otro significa aceptarlo y confirmarlo como un sí mismo, ayudarle a lograr su autonomía desde un sentimiento profundo, desde el interior, en este caso dotándole de libertad para realizar sus ciclos sin que el principal interés sea el económico, sino el de satisfacción de la necesidad primaria. El reconocimiento como confirmación, para Ricoeur, inicia al sujeto en un camino hermenéutico en el que comienza por reconocerse a sí mismo. En este caso se lograría mediante la comunión del ser humano con el ser del medioambiente. Se busca la confianza y la aceptación reflejándose en la mirada del otro así como el otro pudiera verse reflejado en la de uno mismo. Una mirada llena de valor que escape por todos los medios a cualquier aspecto relacionado con la dominación. Para la creadora del concepto "ecofeminismo", Françoise d'Eaubonne, uno de los principales enemigos del planeta es el poder masculino, que constituye el principal sistema dominante. Tanto la mujer como el ecosistema han estado sometidos al hombre durante mucho tiempo. Sostiene que el patriarcado, en el capitalismo, toma la forma de esa voracidad que devora el mundo. Critica el consumo como la voluntad de poder del patriarcado capitalista. El ecofeminismo nace a partir de la reivindicación del derecho sobre el propio cuerpo. Y morirá si no apoyamos la reivindicación por parte del medioambiente, ya que por sí mismo no puede combatir el sistema patriarcal de producción, conducente a una crisis ecológica que terminaría por afectarnos a todos si no ponemos los medios necesarios. Esto en parte estaría dando respuesta a la segunda pregunta, si la naturaleza debe ser protegida para ella o para los seres humanos liberados. El ecofeminismo representa una doble lucha; la de la igualdad y la de la protección del mundo natural. El primer principio que se ha de tener en cuenta es el reconocimiento de la Tierra como un ser vivo que sostiene todas las vidas, incluyendo también las actividades productoras de explotación que ejercemos contra él; es decir, que además de sostener, soporta.

No tiene excusa para no producir sus verduras." Núria NAVARRO. "No hay otra libertad que la resistencia pasiva". El periódico de Cataluña. 25 de junio de 2007. 
BiBLIOGRAFÍA

AMORÓS, Celia. Feminismo y filosofía. Madrid. Síntesis. 2000. p. 144

HONNETH, Axel. Struggle for Recognition. Trad. Ingl. Joel Anderson. Struggle for Recognition. Oxford. Polity Press. 1995

JACORZYNSKY, Witold. Entre los sueños de la razón: filosofía y antropología de las relaciones entre hombre y ambiente. México. CIESAS. 2004

LÓPEZ DE LA VIEJA DE LA TORRE, Ma Teresa. Bioética y feminismo. Estudios multidisciplinares de género. Salamanca. Universidad de Salamanca. 2006

LÓPEZ DE LA VIEJA DE LA TORRE, Ma Teresa. Feminismo: del pasado al presente. Salamanca. Universidad de Salamanca. 2000

NAVARRO, N. "No hay otra libertad que la resistencia pasiva". El periódico de Cataluña. 25 de junio de 2007

PULEO, Alicia H. “Objetividad y género”. Filosofía, género y pensamiento crítico. Valladolid. Universidad de Valladolid. 2000

RICOEUR, P. Parcours de la reconnaissance. Trois études. París. Stock, 2004

RICOEUR, Paul. Philosophie de la volonté II. Finitude et culpabilité. París. Éditions Montaigne. 1988

SHIVA, Vandana. Abrazar la vida. Mujer, ecología y aupervivencia. Madrid. Horas y horas, D.L. 1995

STOLZE, Natalia. "Sadou Shakrah”. Wanafrica. Febrero de 2007

WARREN, Karen J. Filosofías ecofeministas. Barcelona. Icaria. 2003

WEBER, Max. La ética protestante y el espiritu del capitalismo. Barcelona. Península. 1993 